\title{
Interactive comment on "Dynamic shape factor and mixing state of refractory black carbon particles in winter in Beijing using an AAC-DMA-SP2 tandem system" by Xiaole Pan et al.
}

Xiaole Pan et al.

panxiaole@mail.iap.ac.cn

Received and published: 7 October 2019

The comment was uploaded in the form of a supplement:

https://www.atmos-chem-phys-discuss.net/acp-2019-433/acp-2019-433-AC4-

supplement.pdf 